\title{
DETERMINAÇÃO DA BACTERIOCLOROFILA E DA CONCENTRAÇÃO CELULAR DAS BACTÉRIAS PÚRPURAS NÃO SULFUROSAS Rhodobacter Rhodopseudomonas palustris
}

\section{P. BESSA ${ }^{1}$, L. M. VIEIRA ${ }^{1}$, F. T. M. SILVA ${ }^{2}$, J. S. FERREIRA ${ }^{3}$, VICELMA, L.C. ${ }^{3}$, F. R.} X. BATISTA ${ }^{3}$

${ }^{1}$ Universidade Federal de Uberlândia, Graduação em Engenharia Química

${ }^{2}$ Universidade Federal de Uberlândia, Pós Graduação em Engenharia Química

${ }^{3}$ Universidade Federal de Uberlândia, Professoras da FEQUI/UFU

E-mail para contato: lidiane.lpb2@gmail.com; lucas.mendes09@hotmail.com

\begin{abstract}
RESUMO - As bactérias púrpuras não sulfurosas são micro-organismos dependentes da luz e se destacam pela habilidade de realizar fotossíntese, convertendo através da radiação solar, água, compostos de enxofre ou compostos orgânicos em hidrogênio. Tais indivíduos realizam em anaerobiose, através da fotofermentação, a produção deste biocombustível $\left(\mathrm{H}_{2}\right)$ associada à liberação de energia a partir de açúcares e outras moléculas orgânicas. Sendo a bacterioclorofila um pigmento diretamente responsável por estes processos e devido a sua capacidade de absorção luminosa, o presente estudo buscou quantificar este pigmento juntamente com a determinação da concentração celular das cepas $R$. capsulatus e $R$. palustris, obtendo assim informações essenciais para um melhor entendimento metabólico do sistema.
\end{abstract}

\section{INTRODUÇÃO}

As bactérias púrpuras não sulfurosas (PNS), Rhodopseudomonas palustris e Rhodobacter capsulatus, pertencentes à família das Rhodospirillaceae, se destacam na produção de hidrogênio, sendo este, um combustível renovável (Carlozzi et al., 2006). Nos processos fotossintéticos estes micro-organismos dependentes da luz, utilizam a radiação solar para converter água, compostos de enxofre ou compostos orgânicos em hidrogênio, sob condições anaeróbias (Silva et al., 2009). Na rota para produção de hidrogênio por fotofermentação, ocorre a liberação de energia a partir de açúcares ou outras moléculas orgânicas, como aminoácidos e ácidos orgânicos, em condições anaeróbicas e com concentração baixa de nitrogênio. A síntese biológica de hidrogênio tem sido pesquisada no sentido de tornar a produção deste biocombustível técnica e economicamente viável (Argun e Kargi, 2011).

Nas bactérias que realizam fotossíntese a captação da energia solar fica a cargo da bacterioclorofila, que é o pigmento primário da $R$. capsulatus e da $R$. palustris. As bacterioclorofilas que são responsáveis pela fotossíntese anoxigênica têm as mesmas funções das clorofilas nas plantas, ou seja, são responsáveis pela absorção da energia luminosa. Assim, excitam alguns elétrons das moléculas que, em seguida, são transferidos por 
carregadores de elétrons $\left(\mathrm{NAD}^{+}, \mathrm{NADP}^{+}\right.$e FAD), e durante essa fase há produção de ATP. Os elétrons são transferidos dos carregadores para seus aceptores finais de elétrons que, no caso da fermentação, são os compostos orgânicos. As bacterioclorofilas mais comuns em bactérias púrpuras são as bacterioclorofilas A e B, sendo que estas absorvem a luz em comprimentos de onda superiores àqueles absorvidos pela clorofila a. Estas bacterioclorofilas estão localizadas em invaginações da membrana plasmática, os cromatóforos (Tortora et al., 2012).

Para cepas de PNS é possível determinar a presença de bacterioclorofila, utilizando-se o método de extração simples por solventes orgânicos (acetona e/ou metanol). Medindo-se a absorbância por espectrofotometria em um comprimento de onda adequado e através de cálculos simples, é possível obter a concentração deste pigmento nas amostras. Tratando-se de uma amostra pura, ou seja, cultivada em laboratório em condições controladas, este método mostra-se eficaz tanto para a extração como para a quantificação da bacterioclorofila. Por outro lado, em amostras de ambientes naturais, o erro associado a esta medida pode torna-se acentuado (Stal et al., 1984). Um exemplo de determinação do teor de pigmentos de agentes fotossintetizantes é o trabalho realizado por Stal et al. (1984). Estes autores avaliaram a extração do pigmento com solventes orgânicos (metanol, metanol $/ \mathrm{NaCl}$ e hexano) e para isso utilizaram duas cepas de cianobactérias (Plectonema boryanum e Anabaena) e diversas cepas de bactérias fotossintetizantes anaeróbicas (Chromatium Vinosum, Chlorobium limicola, Chlorobium vibrioforme, Chlorobium phaeobacterioide e Thiocapsa roseopersicina). Sendo que, cianobactérias contêm clorofila A, $C$. vinosum e $T$. roseopersicina contêm bacterioclorofila A, e ainda, C. limicola, C. vibrioforme e C. phaeobacteroides contêm bacterioclorofilas $\mathrm{C}, \mathrm{D}$ e $\mathrm{E}$, respectivamente.

No presente trabalho foi determinada a concentração de bacterioclorofila A (BChla), sendo esta a principal responsável pela produção de hidrogênio nas cepas Rhodopseudomonas palustris e Rhodobacter capsulatus. De forma complementar, tal determinação foi correlacionada com a cinética de crescimento celular.

\section{MATERIAIS E MÉTODOS}

\subsection{Micro-organismo e Condições de Cultura}

Os micro-organismos Rhodobacter capsulatus DSM 1710 e Rhodopseudomonas palustris DSM 123, utilizados ao longo deste estudo, foram cultivados em meio basal RCV (Weaver et. al., 1975), cuja composição está descrita nas Tabelas 1 e 2. As bactérias foram mantidas a $30^{\circ} \mathrm{C}$ em condição de anaerobicidade e com intensidade luminosa de 2200 lux.

Os experimentos para determinação da concentração de bacterioclorofila A (BChla) e concentração celular foram efetuados a partir de inóculos das cepas $R$. palustris e $R$. capsulatus. Para estas determinações, amostras da suspensão celular foram retiradas em intervalos de tempo de 21 dias, registrados a partir do repique das bactérias. 
Tabela 1 - Componentes do meio RCV

\begin{tabular}{lc}
\hline \multicolumn{1}{c}{ Reagente } & $\begin{array}{c}\text { Concentração } \\
(\mathrm{g} / \mathrm{L})\end{array}$ \\
\hline Ácido Málico & 4,02 \\
$\mathrm{KH}_{2} \mathrm{PO}_{4}$ & 0,60 \\
$\mathrm{~K}_{2} \mathrm{HPO}_{4}$ & 0,90 \\
$\mathrm{MgSO}_{4} \cdot 7 \mathrm{H}_{2} \mathrm{O}$ & 0,12 \\
$\mathrm{CaCl}_{2} \cdot 2 \mathrm{H}_{2} \mathrm{O}$ & 0,075 \\
$\mathrm{Na}_{2} \mathrm{EDTA}_{2} 2 \mathrm{H}_{2} \mathrm{O}$ & 0,02 \\
$\mathrm{Micronutrientes}$ & $1 \mathrm{~mL}$ \\
$\mathrm{Tiamina}$ & 0,001 \\
$\left(\mathrm{NH}_{4}\right)_{2} \mathrm{SO}_{4}$ & 1 \\
\hline
\end{tabular}

Tabela 2 - Composições da solução de micronutrientes utilizada no meio RCV

\begin{tabular}{lc}
\hline \multicolumn{1}{c}{ Reagente } & $\begin{array}{c}\text { Concentração } \\
(\mathrm{g} / \mathrm{L})\end{array}$ \\
\hline $\mathrm{H}_{3} \mathrm{BO}_{3}$ & 2,8 \\
$\mathrm{MnSO}_{4} \mathrm{H}_{2} \mathrm{O}$ & 1,59 \\
$\mathrm{NaMoO}_{4} 2 \mathrm{H}_{2} \mathrm{O}$ & 0,75 \\
$\mathrm{ZnSO}_{4} 7 \mathrm{H}_{2} \mathrm{O}$ & 0,24 \\
$\mathrm{CaCl}_{2} \cdot 2 \mathrm{H}_{2} \mathrm{O}$ & 0,075 \\
$\mathrm{CuCl}_{2} 2 \mathrm{H}_{2} \mathrm{O}$ & 0,05 \\
\hline
\end{tabular}

\subsection{Determinação da Bacterioclorofila $A$}

Para a análise da BChla os experimentos foram realizados em quadruplicata, a partir de uma adaptação do procedimento adotado por Takahushi e Ichimura (1970), segundo discutido por Picazo et al. (2013). Para cada análise, amostras de $10 \mathrm{~mL}$ do inóculo foram centrifugadas a $3500 \mathrm{rpm}$ durante $10 \mathrm{~min}$, obtendo-se assim as células como corpo de fundo e o meio no qual elas se mantinham, como sobrenadante.

O sobrenadante foi então descartado e uma solução extratora composta por acetona/metanol $(90: 10$, em $\% \mathrm{v} / \mathrm{v})$ foi adicionada. Em seguida, o material foi mantido ao abrigo da luz para se evitar qualquer tipo de degradação do pigmento. Posteriormente, o material foi levado ao sonicador. Após 30 minutos no equipamento, as amostras foram armazenadas em um freezer e mantidas à temperatura de $-18{ }^{\circ} \mathrm{C}$ por 20 horas. Ao retirar as amostras do freezer, estas foram filtradas (PTFe de $0,2 \mu \mathrm{m}$ ) com o auxílio de seringas. A absorbância do filtrado foi medida em um espectrofotômetro, no comprimento de onda de 772 $\mathrm{nm}$, utilizando para tal uma cubeta de quartzo. O teor e a produção específica de BChla são dados pelas Equações (1) e (2), respectivamente:

$$
\begin{aligned}
& \text { BChla }\left(\frac{m g}{m^{3}}\right)=25,2 \times D O_{772} \times \frac{v}{V} \\
& \text { Produção específica }\left(m g \text { BChla } / g \text { célula) }=\frac{\text { Concentração de BChla }\left(\frac{m g}{m^{3}}\right)}{\text { Concentração de célula }\left(\frac{g}{L}\right) \times 1000}\right.
\end{aligned}
$$


Na Equação (1), BChla é a concentração de bacterioclorofila $\mathrm{A}, \mathrm{DO}_{772}$ é a densidade óptica medida a $772 \mathrm{~nm}$, v é o volume de solvente acetona:metanol (90:10, \%v/v) usado na extração e V é o volume total da amostra (Takahushi e Ichimura, 1970; Picazo et al., 2013).

\subsection{Determinação da Concentração Celular}

A determinação da concentração das bactérias foi realizada através do método gravimétrico, correlacionando a medida da absorbância do inóculo das bactérias através de um espectrofotômetro e a concentração celular (g/L), segundo Oliveira et al. (2013). A densidade óptica a $660 \mathrm{~nm}\left(\mathrm{OD}_{660}\right)$ foi medida em um espectrofotômetro (Genesys).

\section{RESULTADOS E DISCUSSÕES}

As variações da concentração celular e do teor de BChla em função do tempo são apresentadas nas Figuras 1(a) e 1(b), respectivamente, para $R$. palustris e $R$. capsulatus. A produção específica (mg BChla/g célula) é ilustrada nas Figuras 2(a) e 2(b), para R. palustris e $R$. capsulatus, respectivamente.

Figura 1 - Variação de concentração celular e de BChla em função do tempo. (Média com IC95\% - Intervalo de confiança nível 95\%)

(a) Rhodopseudomonas palustris

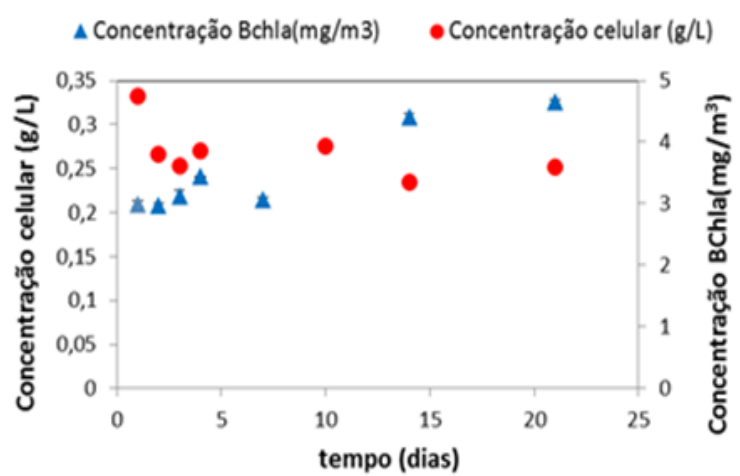

(b) Rhodopseudomonas capsulatus

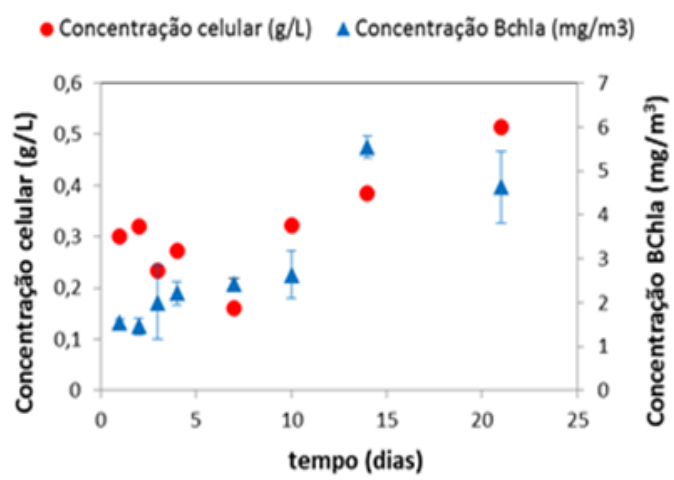

Pela análise da Figura 1, observa-se que a cultura de $R$. palustris (1a) não apresentou aumento na concentração celular. Tal comportamento pode ser atribuído à morte de células e a dificuldade de adaptação ao novo meio que lhe foi adicionado. Observou-se que a concentração se manteve constante em cerca de $0,26 \mathrm{~g} / \mathrm{L}$ após 2 dias de cultivo. Já a cultura de $R$. capsulatus (1b), após uma pequena queda inicial, apresentou crescimento celular a partir do $7^{\circ}$ dia de cultivo, atingindo cerca de $0,5 \mathrm{~g} / \mathrm{L}$.

Com relação à concentração de BChla, mesmo com a queda da concentração celular, o teor de BChla aumenta ao longo do período de cultivo, tendo-se o valor de 4,73 $\pm 0,03 \mathrm{mg}$ $\mathrm{BChla} / \mathrm{m}^{3}$ e $4,63 \pm 0,82 \mathrm{mg} \mathrm{BChla} / \mathrm{m}^{3}$, para $R$. palustris e $R$. capsulatus, respectivamente. Faz-se necessário buscar uma maior compreensão da relação crescimento celular e das condições de cultivo com a produção da BChla, uma vez que este pigmento está diretamente 
ligado com a eficiência de conversão de luz, favorecendo a produção de produtos como hidrogênio e demais metabólitos (ácidos orgânicos e álcoois), com vasta aplicação industrial e de importância econômica.

Comparando com a literatura, pode-se citar o trabalho desenvolvido por Carlozzi et al. (2006), que estudaram o crescimento de $R$. palustris e sua produção de hidrogênio em meio modificado van Niel. Eles observaram que não houve produção de BChla até as primeiras 24 $\mathrm{h}$, sendo que a concentração de BChla aumentou até $72 \mathrm{~h}$ (fase $\log$ ), atingindo a fase estacionária com $10 \mathrm{mg} / \mathrm{L}$, para uma concentração final de cerca de $1,0 \mathrm{~g} / \mathrm{L}$.

Figura 2 - Produção específica de BChla por R. palustris e R. capsulatus.

(a) Rhodopseudomonas palustris

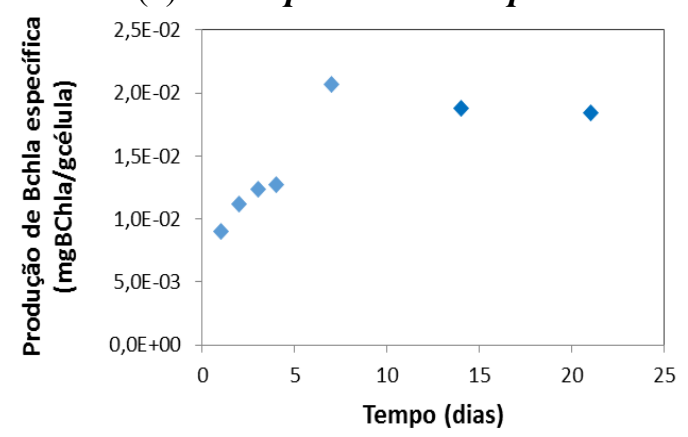

(b) Rhodopseudomonas capsulatus

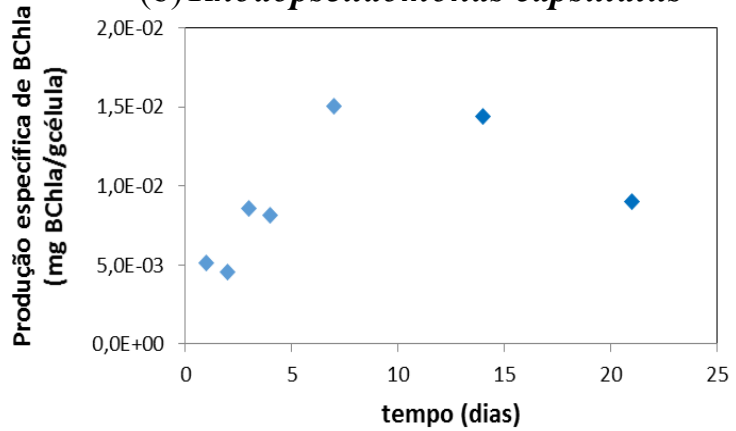

Analisando a produção específica de BChla (mg/g célula) pela Figura 2, é possível notar que mesmo com o crescimento celular inicial que ocorreu para ambas as cepas, as células produziram o pigmento. Para $R$. palustris, a produção específica se manteve constante após 7 dias, Figura 2(a). Observa-se pela Figura 2(b) um aumento da produção específica até 15 dias de cultiva da $R$. capsulatus, havendo uma queda ao final dos 21 dias, podendo ser justificado pelo crescimento celular desta cepa (Figura 1b), o que não foi observado para a $R$. palustris.

\section{CONCLUSÕES}

Este trabalho determinou a concentração de bacterioclorofila a de bactérias púrpuras não sulfurosas, $R$. capsulatus e $R$. palustris, através de um método que se mostrou rápido e prático. $\mathrm{O}$ acompanhamento da concentração deste pigmento durante os processos que empregam estes agentes fotossintetizantes pode contribuir para esclarecer e avaliar as condições para se elevar a eficiência de conversão de luz e, portanto, melhorar a eficiência de processos como a produção de hidrogênio por fotofermentação.

\section{AGRADECIMENTOS}

Os autores agradecem a Universidade Federal de Uberlândia e a Faculdade de Engenharia Química pela oportunidade em realizar este trabalho. Agradecem também ao apoio financeiro da FAPEMIG, do CNPq e da CAPES. 


\section{REFERÊNCIAS}

ARGUN, H.; KARGI, F. Bio-hydrogen production by different operational modes of dark and photo-fermentation: An overview. International Journal of Hydrogen Energy, v. 36, p. 7443-7459, 2011.

CARLOZZI, P.; PUSHPARAJ, B.; DEGL'INNOCENTI, A.; CAPPERUCCI A. Biotechnological products and process engineering. Springer-Verlag, 2006.

OLIVEIRA, T.V.; OLIVEIRA, F. S.; SOUSA, T. M.; FERREIRA, J. S.; BATISTA, F. R. X.; CARDOSO, V. L. Avaliação da potencialidade da produção de hidrogênio através do uso da bactéria fotossintetizante Rhodobacter capsulatus. In anais da XVII Jornada em Engenharia Química (JORNEQ), Uberlândia, 2013.

PICAZO A.; ROCHERA C.; VICENTE, E.; MIRACLE, M. R.; CAMACHO, A. Spectrophotometric methods for the determination of photosynthetic pigments in stratified lakes: a critical analysis based on comparisons with HPLC determinations in a model lake. Limnetica, v. 32, p. 139-158, 2013.

SILVA, G. M.; SILVA, L. G. M.; OIKNINE, L.; DASSOLER, T. S.; FURIGO Jr, $A$. Produção Biotecnológica de Hidrogênio. CTDEQA/UFSC, Florianópolis, 2009.

STAL, J. L.; GEMERDEN, H.; KRUMBEIN, E. W., The simultaneous assay of clorophyll and bacteriochlorophyll in natural microbial communities. Journal of microbiological methods, v. 2, p. 295-306, 1984.

TAKAHUSHI, M.; ICHIMURA, S. Photosynthetic properties and growth of photosynthetic sulfur bacteria in lakes. Limnology and Oceanography, v. 15, p. 929-944, 1970.

TORTORA, G. J.; FUNKE, B. R.; CASE, C. L., Microbiologia $10^{a}$ Edição. São Paulo: ARTMED, 2012.

WEAVER, P.F.; WALL, J.D.; GEST, H. Characterization of Rhodopseudomonas capsulata. Arch. Microbial, v. 105, p. 207-216, 1975. 